\title{
Exploring the Time Trend of Stress Levels While Using the Crowdsensing Mobile Health Platform, TrackYourStress, and the Influence of Perceived Stress Reactivity: Ecological Momentary Assessment Pilot Study
}

Rüdiger Pryss ${ }^{1}$, PhD; Dennis John ${ }^{2}$, Prof Dr; Winfried Schlee ${ }^{3}$, PD, PhD; Wolff Schlotz ${ }^{4}$, PD, PhD; Johannes Schobel ${ }^{1}$, $\mathrm{PhD}$; Robin Kraft ${ }^{1}$, MSc; Myra Spiliopoulou ${ }^{5}$, Prof Dr; Berthold Langguth ${ }^{3}$, Prof Dr; Manfred Reichert ${ }^{1}$, Prof Dr; Teresa O'Rourke ${ }^{6}, \mathrm{BSc}$; Henning Peters ${ }^{7}, \mathrm{MD}, \mathrm{PhD}$; Christoph Pieh ${ }^{6}$, Prof Dr; Claas Lahmann ${ }^{8}$, Prof Dr; Thomas Probst ${ }^{6}$, Prof Dr

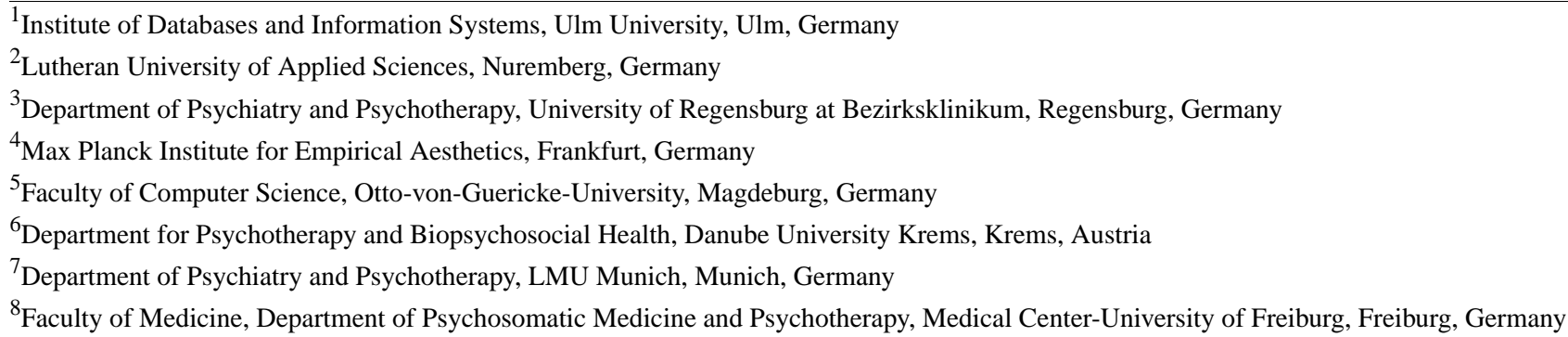

\section{Corresponding Author:}

Rüdiger Pryss, PhD

Institute of Databases and Information Systems

Ulm University

James-Franck-Ring

Ulm, 89081

Germany

Phone: 497315024136

Email: ruediger.pryss@uni-ulm.de

\section{Abstract}

Background: The mobile phone app, TrackYourStress (TYS), is a new crowdsensing mobile health platform for ecological momentary assessments of perceived stress levels.

Objective: In this pilot study, we aimed to investigate the time trend of stress levels while using TYS for the entire population being studied and whether the individuals' perceived stress reactivity moderates stress level changes while using TYS.

Methods: Using TYS, stress levels were measured repeatedly with the 4-item version of the Perceived Stress Scale (PSS-4), and perceived stress reactivity was measured once with the Perceived Stress Reactivity Scale (PSRS). A total of 78 nonclinical participants, who provided 1 PSRS assessment and at least 4 repeated PSS-4 measurements, were included in this pilot study. Linear multilevel models were used to analyze the time trend of stress levels and interactions with perceived stress reactivity.

Results: Across the whole sample, stress levels did not change while using TYS $(P=.83)$. Except for one subscale of the PSRS, interindividual differences in perceived stress reactivity did not influence the trajectories of stress levels. However, participants with higher scores on the PSRS subscale reactivity to failure showed a stronger increase of stress levels while using TYS than participants with lower scores $(P=.04)$.

Conclusions: TYS tracks the stress levels in daily life, and most of the results showed that stress levels do not change while using TYS. Controlled trials are necessary to evaluate whether it is specifically TYS or any other influence that worsens the stress levels of participants with higher reactivity to failure.

(JMIR Mhealth Uhealth 2019;7(10):e13978) doi: $\underline{10.2196 / 13978}$ 


\section{KEYWORDS}

mHealth; psychological stress; crowdsensing; ecological momentary assessment; pilot study

\section{Introduction}

\section{Background}

Selye introduced the term stress as the "nonspecific response of the body to any demand made upon it" [1]. According to the transactional model of stress by Lazarus and Folkman [2], 2 cognitive processes (primary and secondary appraisal) determine the individual experience of stress. Primary appraisal reflects an individual's evaluation of the situation being relevant and potential threats, whereas secondary appraisal reflects an individual's evaluation of manageability of the situation. If the situation is considered relevant and one's own capacities are considered insufficient to deal with the situation, then stress is the consequence. Note that neuroscience showed that stress involves reactions in the central and peripheral nervous system [3].

Continuously elevated stress levels can increase the risk of mental and somatic disease $[3,4]$. Stress levels vary between and within individuals. Individuals differ in their stress levels because of their genetics, developmental experiences, and personality traits to provide only some examples [3]. An important concept in this context constitutes perceived stress reactivity, which has been defined as a disposition that underlies relatively stable individual differences in stress responses. [5]. Within an individual, stress levels can vary depending on, for instance, the severity, intensity, and the frequencies of stressors [3]. Therefore, the assessment of inter- and intraindividual aspects of stress levels is of paramount importance, for example, for reducing the risk to develop mental or somatic disorders.

\section{Objectives}

Ecological momentary assessments (EMAs) of stress levels allow the investigation of these inter- and intraindividual differences under real-life conditions [6]. Although a recent review on mobile phone-based stress assessments included 35 studies [7], validated stress scales were used only in 5 of these studies. In this study, we present the TrackYourStress (TYS) crowdsensing mobile health (mHealth) platform that comprises the short version of the validated Perceived Stress Scale (PSS-4; [8]). Although the PSS-4 received some criticism [9,10], both the reliability and validity were acceptable in a European study [11]. We selected the PSS-4 instead of, for example, longer versions of the PSS [8] or the Perceived Stress Questionnaire (PSQ; [12]) for TYS, as scales for mobile phone-based assessments should be both psychometrically sound and as short as possible, so that participants are willing to fill in the scale continuously over a longer period of time and without (1) any bias because of measurement reactivity or (2) missing data because of missed signals. TYS combines EMAs and crowdsensing by solely using mobile technology and by integrating mobile phone sensors to collect data. In another study [13], we investigated passively sensed environmental data (Global Positioning System [GPS] location of TYS users) as predictors of daily measured stress-related items. In contrast to the previous study, this paper introduces TYS in more detail and reports results of an explorative pilot study on the trajectories of perceived stress levels assessed weekly with the PSS-4 in nonclinical TYS users to investigate measurement reactivity, that is, the extent to which measuring affects the measurement itself. The following 2 research questions (RQ) were addressed:

- $\quad$ RQ1 refers to average measurement reactivity in the total sample: How is the time trend of stress levels when using TYS in the entire population being studied in a first explorative analysis?

- $\quad$ RQ2 refers to interindividual differences in measurement reactivity: Is there an interaction between the time trend of stress levels when using TYS and interindividual differences in perceived stress reactivity? As perceived stress reactivity and stress levels have been shown to be correlated in the cross-sectional research [5], we explored whether the individuals' perceived stress reactivity interacts not only with simultaneously measured stress levels but also with longitudinally measured stress trajectories.

\section{Methods}

\section{Measures}

\section{Perceived Stress Scale}

The PSS-4 [8] was used in this study to operationalize stress levels using repeated measures across at least 4 measurement occasions. Items were scored on a Likert scale ranging from 0 to 4. In items 1 and 4, higher scores indicate more stress (eg, ...how often have you felt that you were unable to control...), but in items 2 and 3, higher scores indicate less stress (eg, ...how often have you felt confident about...). Therefore, items 2 and 3 had to be inverted- $(0=4)(1=3)(2=2)(3=1)(4=0)$ - to calculate the PSS-4 scale score so that higher scores indicate higher stress levels. The PSS-4 was repeatedly assessed on the mobile phone of TYS users. The implemented instruction was to rate the PSS-4 for the last week. The intraclass correlation (ICC) for the PSS- 4 scale scores was rather high at ICC $=0.70$, suggesting a strong between-subject variance component. Using a multilevel confirmatory factor analysis framework [14], we estimated within- and between-subject reliability by calculating 2-level composite reliability (omega), which is appropriate for unit-weighted scoring of congeneric scales [15]. This resulted in $\omega_{\text {within }}=0.60(95 \%$ CI 0.51 to 0.68$)$ and $\omega_{\text {between }}=0.93(95 \%$ CI 0.90 to 0.96$)$.

\section{Perceived Stress Reactivity Scale}

The PSRS [5] was assessed once at the beginning of the study by each TYS user on the mobile phone. It measures stress reactivity, that is, interindividual differences in stress responses. The PSRS consists of 23 items, which were scored on a Likert scale ranging from 0 to 2 . Higher scores indicate more perceived stress reactivity in some items (eg, When tasks and duties build up to the extent that they are hard to manage...), but less perceived stress reactivity in other items (eg, When I want to relax after a hard day at work...). Therefore, the following 
items had to be inverted- $(0=2)(1=1)(2=0)$ - to calculate the perceived stress reactivity subscales and total scale so that higher scale scores indicate higher perceived stress reactivity: Items $2,10,20,8,13,15,18,5,17,19,11,22$. The subscales and their internal consistencies (Cronbach's Alpha) in our sample were as follows: prolonged reactivity (alpha=.76), reactivity to failure (alpha=.63), reactivity to social conflicts (alpha=.74), reactivity to work overload (alpha=.86), and reactivity to social evaluation (alpha=.66). The total scale had an internal consistency (Cronbach alpha) of alpha $=.87$ in our sample.

\section{TrackYourStress Mobile Health Crowdsensing Platform}

TYS is an mHealth crowdsensing platform, which offers a website (registration and account management), an Android and iOS mobile app, a MariaDB relational database for the central repository to store the collected data, and a sophisticated Representational State Transfer (ie, RESTful) application program interface (API) for communication between the mobile apps, website, and database. A total of 4 questionnaire types, all related to stress, were implemented and integrated into TYS, namely registration, daily, weekly, and monthly questionnaire. In addition, the environmental sound level and the GPS position can be measured by the mobile apps, but TYS users must allow these sensor measurements when registering to TYS.

The applied procedure for all TYS users, in turn, is as follows: First, they register through the website or the mobile apps. Second, users have to fill in the registration questionnaire once.
This includes demographic data (eg, gender and date of birth), the PSS-4, the PSRS, and the coping scales of the Stress and Coping Inventory (SCI; [16]). In a future version of TYS, a personality measure will be included in the registration questionnaire as well. Following the completion of the registration questionnaire the continuous mobile crowdsensing procedure starts, that is, filling out daily, weekly, and monthly questionnaires as well as automatically measuring the environmental sound level and GPS position. Note that the questions of the daily questionnaire can be obtained from Table 1. In particular, 3 basic user interface elements were implemented to answer a question by a TYS user. First, we implemented sliders, which represent the Visual Analogue Scales. Second, only for Question 5 What stresses you at the moment? we implemented a user interface element called Category, which, in turn, shows the following 4 categories to a TYS user: nothing, work-related matters, private matters, other. The user can then select all those categories, which are currently stressful for him or her. Third, we implemented a user interface element to provide the so-called Self-Assessment Manikins (SAM) [17] on Android and iOS. The SAM, in turn, are built on pictograms and used in psychology to measure emotions. To get a better impression of selected user interface elements, Figure 1 shows how the questionnaires are presented on the 2 mobile operating systems. Finally, note that the weekly questionnaire includes the PSS-4, whereas the monthly questionnaire includes the coping scales of the SCI.

Table 1. Items of the TrackYourStress daily questionnaire.

\begin{tabular}{lll}
\hline Number & Question & Scale \\
\hline 1 & How high is your momentary stress level? & VAS $^{\text {a }}$ \\
2 & How well can you control your momentary stress level? & VAS \\
3 & How strongly are you experiencing your momentary stress level as negative/impairing? & VAS \\
4 & How strongly are you experiencing your momentary stress level as positive/beneficial? & VAS \\
5 & What stresses you at the moment? & C $^{\text {b }}$ \\
6 & How is your mood right now? & SAM \\
7 & How is your arousal right now? & SAM \\
8 & How important is the current situation for you personally? & VAS \\
9 & How would you assess your ability to cope with the currently experienced situation? & VAS \\
\hline
\end{tabular}

${ }^{\mathrm{a}}$ VAS: Visual Analogue Scale.

${ }^{\mathrm{b}} \mathrm{C}$ : categories.

${ }^{\mathrm{c}}$ SAM: Self-Assessment Manikins [17]. 
Figure 1. Impression of the daily assessment questionnaire (left Android; right iOS).

\section{8:56 \\ TrackYourStress \\ Track your Stress - Daily Questionnaire}

\begin{abstract}
Please answer each question by indicating your current situation in the best possible way
\end{abstract}

\section{How high is your momentary stress-level?

very low very high

How well can you control your momentary stress-level?

not at all very strongly

$07: 594$

Back
$11 \%$

Track your Stress - Daily Questionnaire Please answer each question by indicating your current situation in the best possible way

How high is your momentary stress-level?

\section{How well can you control your momentary stress-level?}

$$
\text { not at all very strongly }
$$

How strongly are you experiencing your momentary stress-level as negative/impairing?

How strongly are you experiencing your momentary stress-level
as negative/impairing?
$\begin{array}{ll}\text { not at all very strongly }\end{array}$

For the crowdsensing procedure, users have to accept or select a predefined notification schema. It determines the frequency and in what way (ie, fixed or random points in time) the daily, weekly, and monthly questionnaires are applied. Each time a notification appears, the user may click on it to start the mobile app (if not already running), and the respective questionnaire (daily, weekly, or monthly) is then directly shown to the user. Then, he/she can fill in the questionnaire. It is also possible for users to fill in the questionnaires without notifications. While filling out the questionnaire, either with or without using a notification, the GPS position and the environmental sound level are measured (if the app is allowed to measure them). After completion, the results are transferred to the database through the RESTful API if the mobile app is on the Web,

not at all

very strongly

How strongly are you experiencing your momentary stress-level as positive/beneficial?

otherwise the results are locally stored until the device gets a Web-based connection. For a detailed technical description of these features see $[18,19]$. The website and the RESTful API of TYS are publicly released, whereas the smart mobile apps are not yet distributed through the official mobile app stores from Apple and Google. Therefore, we used a TestFlight-based distribution for iOS and downloadable Android packages for Android. Presently, TYS is only available in German; however, we are currently translating it to English. Figure 2 summarizes the data collection procedure for TYS with its implemented and planned features. Regarding TYS in general, 2 further important aspects are finally mentioned. First, the source code of TYS is currently not freely available but will be released to the research community in the near future (ie, after several aspects have been 
added for using it more conveniently; eg, by adding English as another possible language to the platform). Second, we plan to use TYS for several other purposes beyond this study. For example, it is planned to offer it to companies to anonymously track the stress levels of their employees over time. Furthermore, it is planned to give individuals the possibility to adjust the existing questionnaires to their individual needs. If they feel that other questions would fit better to their individual situation, then they should be able to adjust the daily, weekly, and monthly questionnaire. In addition, it is planned to integrate more sensors like the ones from Empatica (eg, [20]) to provide even more opportunities to the TYS users.

Figure 2. TrackYourStress mobile crowdsensing collection procedure.

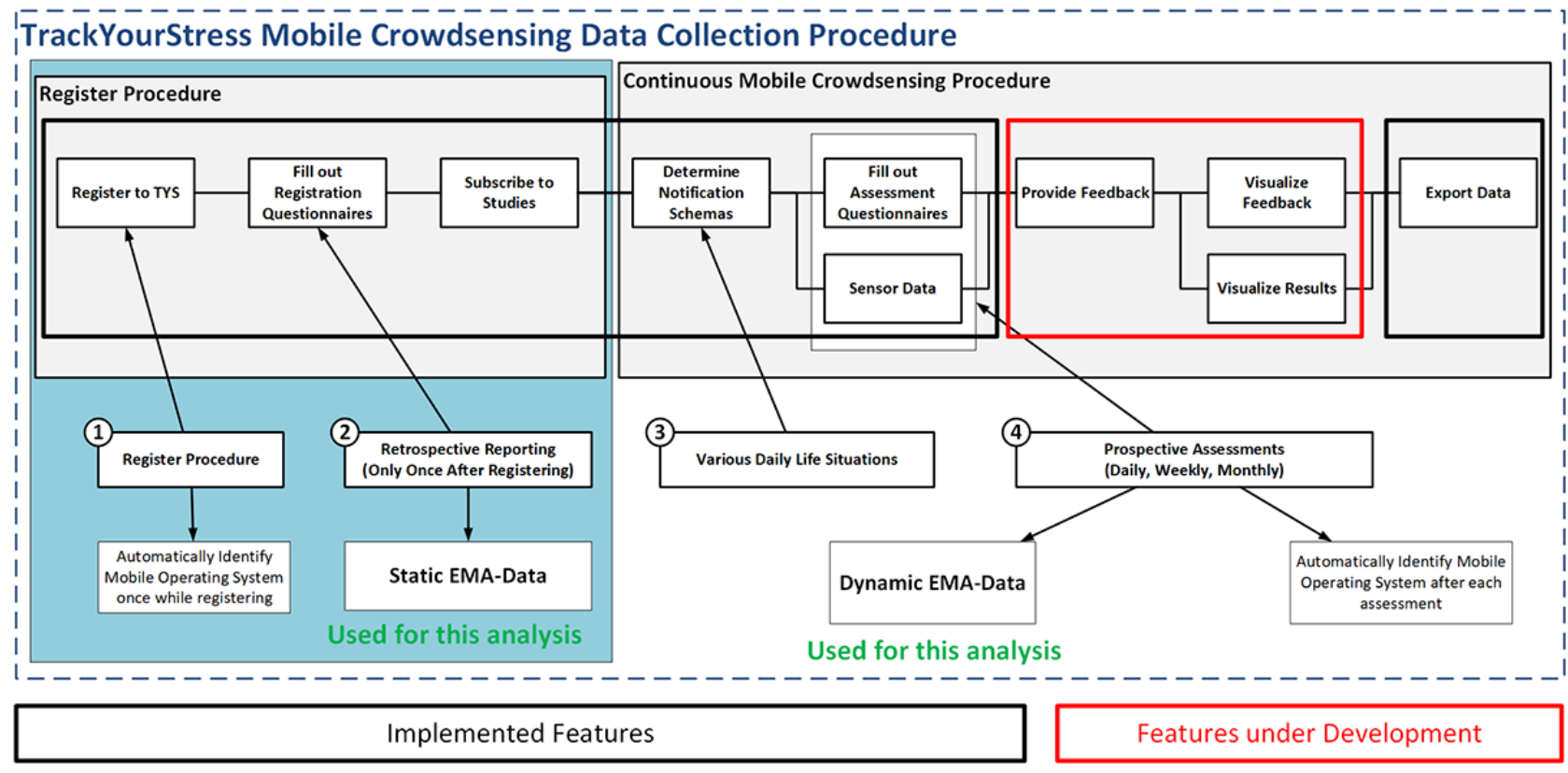

\section{Study Design}

A total of 3 students of the FOM University of Applied Sciences in Augsburg and Munich (Germany) recruited participants. The 3 students asked their social networks (students, friends, family members, and colleagues) whether they are interested to partake in the study. Participants interested to partake first had to provide written informed consent before they got access to TYS. They downloaded the app and went through the TYS procedure as described earlier. The participants were informed that they should use TYS for at least 4 weeks in their daily life.

\section{Participants}

After excluding test users, $\mathrm{N}=113$ individuals used TYS for this study. The participants were asked to provide at least 5 PSS-4 assessments during the study interval, that is, filling in the PSS-4 in the TYS registration questionnaire and filling in at least 4 weekly TYS questionnaires in the upcoming weeks. One weekly
TYS questionnaire less than intended was tolerated to address the RQs. Therefore, the inclusion criteria for this study were filling in the PSRS and the PSS-4 in the registration questionnaire and completing at least three weekly questionnaires including the PSS-4. We deleted all PSS-4 assessments given within an interassessment interval of 24 hours, as some users filled in the PSS- 4 several times a day. This resulted in a sample of 78 participants for this study. The sample description is provided in Table 2 as is the comparison between included $(n=78)$ and excluded study participants $(n=35)$ in baseline variables (gender, age, PSS-4 at registration, and PSRS scales at registration). Included and excluded participants differed in age, with included participants being significantly older than excluded participants $(P=.005)$. The corresponding effect size was medium (Hedges $g=0.52$ ). No significant differences emerged for gender, stress level at registration, and perceived stress reactivity at registration. 
Table 2. Sample description and statistical comparisons between included and excluded participants in baseline variables.

\begin{tabular}{|c|c|c|c|c|}
\hline \multirow[t]{2}{*}{ Variable } & \multirow[t]{2}{*}{ Included sample $(\mathrm{n}=78)$} & \multirow[t]{2}{*}{ Excluded sample $(n=35)$} & \multicolumn{2}{|l|}{ Values } \\
\hline & & & $t(d f)$ & $P$ value \\
\hline Female, n (\%) & $50(64.1)$ & $15(44.1)$ & $-^{\mathrm{a}}$ & $.06^{\mathrm{b}}$ \\
\hline Age (years), mean (SD) & $35.04(12.30)$ & $28.98(9.22)$ & $-2.90(85.82)$ & .005 \\
\hline PSS-4 ${ }^{\mathrm{c}}$, mean (SD) & $5.32(3.00)$ & $5.17(3.18)$ & $-0.24(111)$ & .81 \\
\hline PSRS $^{\mathrm{d}}$ prolonged reactivity, mean (SD) & $2.81(1.97)$ & $2.94(1.80)$ & $0.35(111)$ & .73 \\
\hline PSRS reactivity to failure, mean (SD) & $4.73(1.58)$ & $4.54(1.63)$ & $-0.58(111)$ & .57 \\
\hline PSRS reactivity to social conflicts, mean (SD) & $6.32(2.21)$ & $5.69(2.40)$ & $-1.37(111)$ & .17 \\
\hline PSRS reactivity to work overload, mean (SD) & $3.60(2.65)$ & $3.06(2.27)$ & $-1.06(111)$ & .29 \\
\hline PSRS reactivity to social evaluation, mean (SD) & $4.59(2.46)$ & $4.06(2.51)$ & $-1.06(111)$ & .29 \\
\hline PSRS total, mean (SD) & $22.05(7.69)$ & $20.29(8.29)$ & $-1.10(111)$ & .27 \\
\hline
\end{tabular}

${ }^{\mathrm{a}}$ Not applicable.

${ }^{\mathrm{b}}$ Fisher exact test.

${ }^{\mathrm{c}}$ PSS: Perceived Stress Scale.

${ }^{\mathrm{d}}$ PSRS: Perceived Stress Reactivity Scale.

Our average PSS-4 baseline score of 5.32 is comparable with a previously reported mean of 5.43 based on a large sample of $\mathrm{N}=37,451$ participants [11]. A $t$ test using the means, standard deviations, and sample sizes showed that our PSS-4 mean is not significantly different $\left(t_{37,527}=-0.328 ; P=.74\right)$ from this previously reported one [11]. Our PSRS scores correspond to the ones previously depicted by Schlotz et al (see Figure 2 in their paper) [5] for a German sample between 26 and 60 years. We could not statistically compare the PSRS scores based on means, standard deviations, and sample sizes, as they are only graphically illustrated in the study by Schlotz et al [5].

\section{Statistics}

IBM SPSS v25, Stata v15.1, and Mplus v7.3 were used for statistical analyses. All statistical tests were 2-tailed, and the significance level was set to $P<.05$. To address the RQs, linear multilevel models were used. Multilevel models account for the nested data structure (assessments nested within users), are flexible in handling missing data, do not require the same amount of data points per participants, and do not require equidistant measurement points [21-23]. All multilevel models were calculated with the full maximum likelihood estimation and had assessments as level 1 and participants as level 2. As random terms, the random intercept and the random slope were included in all models, that is, the random slope term makes sure that time is included as a random effect. The unstructured variance-covariance matrix was selected in all models.

To address the RQs, the time variable was coded as follows. The time a user filled in the PSS-4 for the first time (TYS registration) was coded as 0 . The further PSS-4 assessments of a user were coded as the amount of days after his/her first PSS-4 assessment, for example, the time of a PSS-4 assessment provided 8 days after his/her first PSS-4 assessment was coded as 8 and the time of a PSS-4 assessment provided 15 days after his/her first PSS-4 assessment was coded as 15.
For RQ1 (How is the time trend of stress levels when using TYS in the entire population being studied in a first explorative analysis?), the change of PSS-4 over time was evaluated. Therefore, 1 linear multilevel model with the PSS-4 as the dependent variable was performed, which investigated the fixed effect of time (days).

For RQ2 (Is there an interaction between the time trend of stress levels when using TYS and interindividual differences in perceived stress reactivity?), the interaction between time (days) and perceived stress reactivity was in focus. Thereby, 2 linear multilevel models were used. In both models, the PSS-4 was the dependent variable and the fixed effect of time (days) was evaluated. In addition, in 1 multilevel model, the fixed effects of the 5 subscales of the PSRS (time-invariant covariates) and their interactions with time (days) were investigated. In the other multilevel model, the total scale of the PSRS (time-invariant covariate) and its interaction with time (days) were evaluated as fixed effects. In both models, z-standardized PSRS scale scores were used.

\section{Results}

In total, the included $n=78$ participants, who completed at least four PSS-4 assessments, provided 380 PSS-4 assessments in total. On an average, they completed the PSS-4 for a mean 4.87 (SD 0.75) times. The average time interval between 2 consecutive PSS-4 assessments was mean 7.04 (SD 2.70) days. The average time interval between the first and the last PSS-4 assessment of a participant amounted to mean 29.23 (SD 6.77) days.

\section{Results for Research Question 1}

Tables 3 and 4 show the result of the linear multilevel model exploring the time trend of stress levels for the entire population being studied. It can be seen that the stress levels did not change over time when using TYS, since the fixed effect time (days) did not reach statistical significance $(P=.83)$. 
Table 3. Fixed effects of the linear multilevel model evaluating the time trend of perceived stress -levels (PSS-4) while using TrackYourStress.

\begin{tabular}{|c|c|c|c|c|}
\hline \multirow[t]{2}{*}{ Fixed effects } & \multirow[t]{2}{*}{ Estimate } & \multirow[t]{2}{*}{ SE } & \multicolumn{2}{|l|}{ Values } \\
\hline & & & $t$ test $(d f)$ & $P$ value \\
\hline Intercept & 5.397 & 0.344 & 15.677 (78.026) & $<.001$ \\
\hline Time & -0.003 & 0.013 & $-0.211(65.862)$ & .83 \\
\hline
\end{tabular}

Table 4. Random effects of the linear multilevel model evaluating the time trend of perceived stress -levels (PSS-4) while using TrackYourStress.

\begin{tabular}{lllll}
\hline Random effects & Estimate & SE & Values & Wald Z test \\
& & & $P$ value \\
\hline Var(Residual) & 2.247 & 0.218 & 10.326 & $<.001$ \\
$\operatorname{Var}($ Intercept) & 7.910 & 1.485 & 5.328 & $<.001$ \\
Cov(Intercept; time) & -0.064 & 0.043 & -1.480 & .14 \\
$\operatorname{Var}($ Time $)$ & 0.008 & 0.002 & 3.421 & .001 \\
\hline
\end{tabular}

\section{Results for Research Question 2}

Tables 5 and 6 present the results of the linear multilevel model testing interactions between the time trend of PSS-4 stress levels and the PSRS subscales. For the PSRS subscale reactivity to failure, the time $\mathrm{x}$ PSRS interaction was statistically significant $(P=.04)$. Figure 3 illustrates the time trend of stress at different levels of the reactivity to failure subscale and a margin plot showing confidence intervals for the slope parameter at different levels (simple slopes). It can be seen that the higher the individual's reactivity to failure, the more the stress levels increased over time while using TYS, although confidence intervals excluded zero only at relatively low and very high levels. Moreover, increases in the PSRS subscales prolonged reactivity (estimate $=1.030 ; P=.002$ ) and reactivity to work overload (estimate $=0.895 ; P=.02$ ) at baseline and registration respectively were associated with higher PSS-4 stress levels at baseline/registration.

Tables 7 and 8 show the results of the linear multilevel model that evaluated the interaction between the time trend of PSS-4 stress levels and the PSRS total scale. No significant interaction between changes of stress levels over time and the PSRS total scale emerged $(P=.54)$. However, at baseline/registration, higher scores on the PSRS total scale were associated with higher PSS-4 stress levels (estimate $=1.171 ; P<.001$ ).

Table 5. Fixed effects of the linear multilevel model evaluating the time trend of perceived stress- levels (PSS-4) while using TrackYourStress including the 5 subscales of the Perceived Stress Reactivity Scale as z-standardized time-invariant covariates.

\begin{tabular}{|c|c|c|c|c|}
\hline \multirow[t]{2}{*}{ Fixed effects } & \multirow[t]{2}{*}{ Estimate } & \multirow[t]{2}{*}{ SE } & \multicolumn{2}{|l|}{ Values } \\
\hline & & & $t$ test $(d f)$ & $P$ value \\
\hline Intercept & 5.398 & 0.301 & $17.940(78.800)$ & $<.001$ \\
\hline PSRS $^{\mathrm{a}}$ prolonged reactivity & 1.030 & 0.325 & $3.169(79.275)$ & .002 \\
\hline PSRS reactivity to failure & 0.058 & 0.339 & $0.172(78.743)$ & .86 \\
\hline PSRS reactivity to social conflicts & -0.501 & 0.418 & $-1.198(78.715)$ & .24 \\
\hline PSRS reactivity to work overload & 0.895 & 0.382 & $2.342(78.177)$ & .02 \\
\hline PSRS reactivity to social evaluation & 0.393 & 0.368 & $1.069(77.248)$ & .29 \\
\hline Time & -0.003 & 0.012 & $-0.238(65.911)$ & .81 \\
\hline Time $\times$ PSRS prolonged reactivity & -0.004 & 0.014 & $-0.292(73.000)$ & .77 \\
\hline Time $\times$ PSRS reactivity to failure & 0.030 & 0.014 & $2.114(64.951)$ & .04 \\
\hline Time $\times$ PSRS reactivity to social conflicts & 0.009 & 0.017 & $0.502(66.230)$ & .62 \\
\hline Time $\times$ PSRS reactivity to work overload & -0.014 & 0.016 & $-0.883(63.165)$ & .38 \\
\hline Time $\times$ PSRS reactivity to social evaluation & -0.005 & 0.015 & $-0.333(63.636)$ & .74 \\
\hline
\end{tabular}

${ }^{\mathrm{a} P S R S: ~ P e r c e i v e d ~ S t r e s s ~ R e a c t i v i t y ~ S c a l e . ~}$ 
Table 6. Random effects of the linear multilevel model evaluating the time trend of perceived stress- levels (PSS-4) while using TrackYourStress including the 5 subscales of the Perceived Stress Reactivity Scale as z-standardized time-invariant covariates.

\begin{tabular}{lllll}
\hline Random effects & Estimate & SE & Values & Wald Z test \\
& & & $P$ value \\
\hline Var(Residual) & 2.248 & 0.218 & 10.325 & $<.001$ \\
$\operatorname{Var}($ Intercept) & 5.731 & 1.131 & 5.069 & $<.001$ \\
Cov(Intercept; time) & -0.061 & 0.037 & -1.651 & .10 \\
$\operatorname{Var}($ Time) & 0.007 & 0.002 & 3.260 & .001 \\
\hline
\end{tabular}

${ }^{\mathrm{a} P S R S: ~ P e r c e i v e d ~ S t r e s s ~ R e a c t i v i t y ~ S c a l e . ~}$

Figure 3. Illustration of the interaction between time (days) of perceived stress-levels (PSS-4) and the PSRS Reactivity to Failure (RtF) subscale. (A) Estimated simple slopes at $1 \mathrm{SD}$ above and below mean RtF. (B) Margins and $95 \%$ confidence interval for the time trend of stress-levels across a range of RtF scores.

(A)

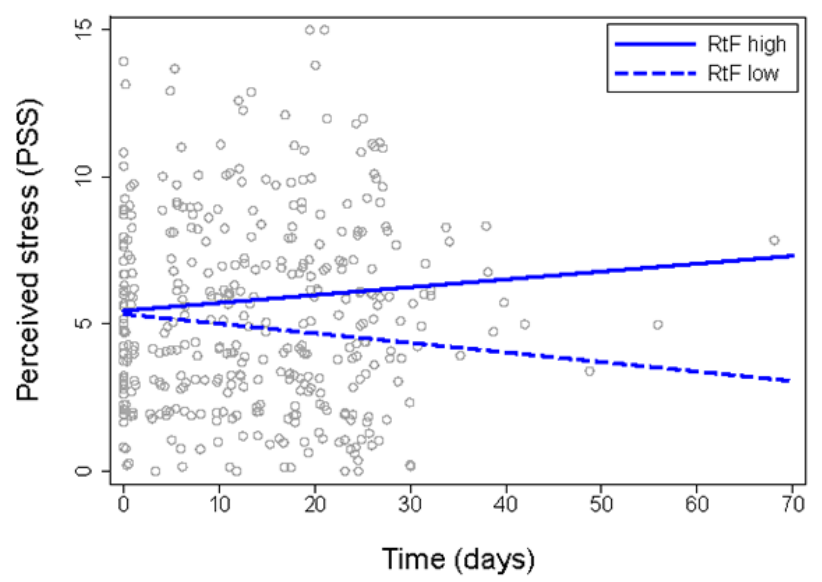

(B)

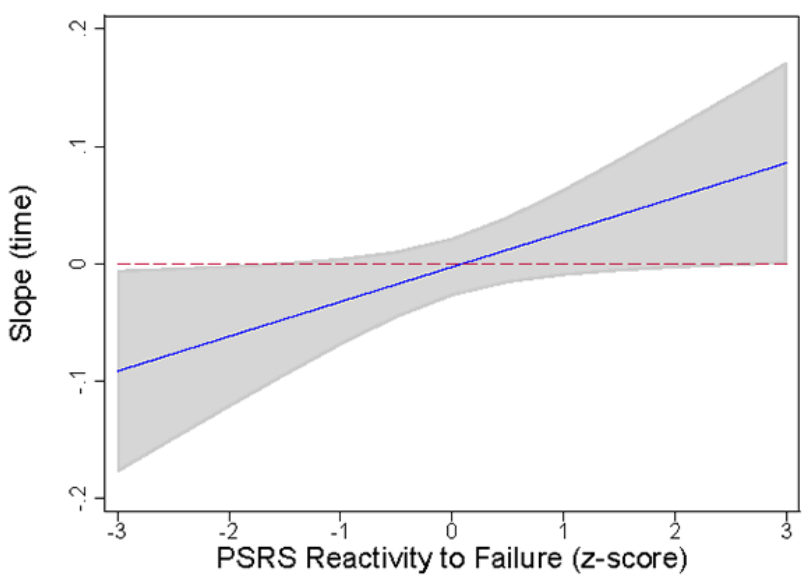

Table 7. Fixed effects of the linear multilevel model evaluating the time trend of perceived stress- levels (PSS-4) while using TrackYourStress including the total scale of the Perceived Stress. Reactivity Scale as z-standardized time-invariant covariate.

\begin{tabular}{|c|c|c|c|c|}
\hline \multirow[t]{2}{*}{ Fixed effects } & \multirow[t]{2}{*}{ Estimate } & \multirow[t]{2}{*}{ SE } & \multicolumn{2}{|l|}{ Values } \\
\hline & & & $t$ test $(d f)$ & $P$ value \\
\hline Intercept & 5.393 & 0.318 & $16.958(78.225)$ & $<.001$ \\
\hline PSRS total $^{\mathrm{a}}$ & 1.171 & 0.320 & $3.658(78.317)$ & $<.001$ \\
\hline Time & -0.002 & 0.013 & $-0.186(65.547)$ & .85 \\
\hline Time $\times$ PSRS total & 0.008 & 0.013 & $0.613(68.266)$ & .54 \\
\hline
\end{tabular}

${ }^{\text {a} P S R S ~ t o t a l: ~ P e r c e i v e d ~ S t r e s s ~ R e a c t i v i t y ~ S c a l e ~ t o t a l ~ s c o r e . ~}$

Table 8. Random effects of the linear multilevel model evaluating the time trend of perceived stress- levels (PSS-4) while using TrackYourStress including the total scale of the Perceived Stress Reactivity Scale as z-standardized time-invariant covariate.

\begin{tabular}{lllll}
\hline Random effects & Estimate & SE & Values & Wald Z test \\
& & & $P$ value \\
\hline Var(Residual) & 2.252 & 0.219 & 10.302 & $<.001$ \\
Var(Intercept) & 6.553 & 1.267 & 5.172 & $<.001$ \\
Cov(Intercept; time) & -0.072 & 0.040 & -1.797 & .07 \\
$\operatorname{Var}($ Time $)$ & 0.008 & 0.002 & 3.382 & .001 \\
\hline
\end{tabular}

${ }^{a}$ PSRS total: Perceived Stress Reactivity Scale total score. 


\section{Discussion}

\section{Principal Findings}

This nonclinical study evaluated the time trend of perceived stress levels while using the crowdsensing mHealth platform, TYS, and the influence of the participants' perceived stress reactivity on longitudinally measured stress trajectories. In a first explorative analysis, we investigated the time trend of stress levels for the entire population being studied. We found no significant change of stress levels over time, and this null finding is in line with the clinical research indicating nonreactivity to EMAs [24-26]. Yet, these results should be interpreted with caution, as no change over time is the null hypothesis in statistical terms. A null hypothesis (here: no change of stress levels over time) cannot be accepted only because of a nonsignificant result; see, for example, work on equivalence and noninferiority testing [27,28]. Moreover, there are no standards on what a true null effect would be (eg, in terms of how narrow a confidence interval has to be), and the power of this study is far too low to test for a narrow confidence interval. In addition, we did not include a control condition and-even if there was no significant change in our study - the time trend of stress levels while using TYS could be significantly different from the time trend of stress levels in a control condition not using TYS.

Second, we analyzed whether interindividual differences in perceived stress reactivity influence the stress level trajectories while using TYS. As stress and stress reactivity were correlated in cross-sectional research [5], we wanted to explore whether the participants' perceived stress reactivity at baseline is associated with longitudinally measured stress trajectories as well. In accordance with [5], we could replicate the cross-sectional correlation between the PSRS total scale and perceived stress levels at baseline, but there were no interactions between the participants' perceived stress reactivity at baseline and the time trend of stress levels when using TYS except for one subscale of the PSRS. The higher the individual's reactivity to failure, the more the stress levels increased while using TYS. More specifically, individuals with higher perceived stress reactivity to failure (eg, mistakes during work) reported an increase in stress levels over a 4-week period. Possibly, individuals with high perceived stress reactivity to failure are more aware of failures in daily routines when monitoring their stress levels in everyday life. Being more aware of stressors in daily life might help individuals with high perceived stress reactivity to adapt their stress responses in the long run [29]. Thus, linking TYS to ecological momentary interventions (EMIs) [30] such as mobile apps for training mindfulness might be a fruitful avenue for future stress research [31-34].

\section{Strengths and Limitations}

Our research design does not allow inferring that it was specifically TYS that increased the stress levels in participants with higher reactivity to failure. There might be several confounders that influenced this result (eg, stressful life events and interpersonal problems with family or friends). This is related to the major limitation of this study, the rather low internal validity because of the lack of a control condition. A randomized controlled trial as for example planned by [35] should be performed with TYS in the future. A randomized controlled trial could compare TYS versus no TYS or specific TYS components with each other, as it could be that specific actions being executed with the TYS solution might be responsible for changes of stress levels.

Another limitation is that the reliability of the PSRS subscale reactivity to failure was rather low in this sample (alpha=.63). In the previous research, the Cronbach alpha values for the PSRS subscale reactivity to failure ranged between alpha $=.65$ and alpha $=.73$. This is likely because of the rather short scale comprising 4 items and might have biased our results. However, it should be noted that reliability estimates of that size are usually sufficient for group studies. Moreover, the external validity of the results is not very high as students of only one university recruited the sample, and the sample size was relatively small. To enhance the generalizability of the results, larger and more representative samples would be welcome. This could be realized by uploading TYS to the app stores. We plan to do this in the next months. Another threat to the external validity is the result that the TYS participants included in the current study were some years older than the TYS participants not meeting the inclusion criteria (mean 35.04 vs mean 28.98). The results might, therefore, be more representative for the TYS users being in their mid-thirties. Furthermore, the sample is rather heterogeneous, as the students recruiting the participants invited fellow students, friends, family members, colleagues, etc, to participate in the study. As we wanted to collect the data as anonymously as possible, the app did not ask about the relationship of the participants to the recruiting students (fellow student, friend, family member, and colleague). Therefore, we could not analyze how the participants' relationship to the recruiting student might have influenced the results. As we cannot find out which of our users were students, we cannot analyze whether seasonality, part of term, or time of year influences the results. This needs to be addressed in future studies. Currently, we intend to perform a study comparing stress levels of students during exam periods with stress levels of students in periods without exams. Furthermore, TYS might be a helpful tool for companies to reduce psychological health problems at the workplace. For example, TYS might help to assess stressors at the workplace and support psychosocial risk assessment. Thus, we intend to build up a large TYS database and to provide personalized feedback to users about their stress levels in relation to their reference group with employees from different companies. Users scoring higher than the reference group could be guided to EMIs (see above), internet-based self-help programs, or to professionals offering face-to-face stress management interventions nearby. It also should be kept in mind that the psychometric properties of the PSS-4 have been criticized $[9,10]$. Our results regarding stress levels solely rely on the self-report PSS-4. Although between-subject reliability of the outcome variable's scores was high, within-subject reliability was at a rather low level $\left(\omega_{\text {within }}=0.60\right)$. This could be because of a number of factors such as the rather high ICC of 0.70 , the relatively small clusters (ie, measurements per person), or the short scale (4 items). Although this reliability might be sufficient for group studies, future versions of the app 
should aim at increasing within-subject reliability of the outcome variable for achieving sufficient reliability of individual assessments. Results would be more robust when a self-report like the PSS-4 is combined with other stress assessment methods such as the Mobile Photographic Stress Meter [36] and objective measures, sensors, and computational methods [37] such as information gained from passive mobile phone sensing [38,39] or physiological signals [40,41]. Integrating such different measures of stress should be a next step in the development of TYS. Moreover, it should be investigated in a larger sample whether there are differences between iOS and Android users with regard to changes of stress levels while using TYS. Previous studies have shown that iOS and Android users differ from each other and this might confound results of mobile phone-based studies [42-44].

\section{Conclusions}

In summary, this study suggested that TYS does not change perceived stress levels in general but that TYS might influence that stress levels increase in individuals with higher reactivity to failure. These results need to be replicated in studies with a control condition and a larger more representative sample.

\section{Acknowledgments}

The authors would like to thank the students N Reineke, K Adler, and M Schönhammer for recruiting the sample.

\section{Authors' Contributions}

RP and TP substantially contributed to the TYS platform and data preparation and drafted and revised the manuscript. DJ substantially contributed to the study design, data acquisition, data interpretation, and revised the manuscript. WS and JS substantially contributed to the TYS platform and data interpretation and revised the manuscript. RK, MS, BL, MR and TO substantially contributed to the TYS platform and revised the manuscript. HP, CP, and CL substantially contributed to data interpretation and revised the manuscript.

\section{Conflicts of Interest}

None declared.

\section{References}

1. Selye H. The evolution of the stress concept. Am Sci 1973;61(6):692-699. [doi: 10.1016/0002-9149(70)90796-4] [Medline: 4746051]

2. Lazarus RS, Folkman S. Stress, Appraisal, and Coping. New York: Springer Publishing Company; 1984.

3. Schneiderman N, Ironson G, Siegel SD. Stress and health: psychological, behavioral, and biological determinants. Annu Rev Clin Psychol 2005;1:607-628 [FREE Full text] [doi: 10.1146/annurev.clinpsy.1.102803.144141] [Medline: 17716101]

4. Cohen S, Janicki-Deverts D, Miller GE. Psychological stress and disease. J Am Med Assoc 2007 Oct 10;298(14):1685-1687. [doi: 10.1001/jama.298.14.1685] [Medline: 17925521$]$

5. Schlotz W, Yim IS, Zoccola PM, Jansen L, Schulz P. The perceived stress reactivity scale: measurement invariance, stability, and validity in three countries. Psychol Assess 2011 Mar;23(1):80-94. [doi: 10.1037/a0021148] [Medline: 21280954]

6. Shiffman S, Stone AA, Hufford MR. Ecological momentary assessment. Annu Rev Clin Psychol 2008 Apr;4(1):1-32. [doi: 10.1146/annurev.clinpsy.3.022806.091415] [Medline: 18509902]

7. Pórarinsdóttir H, Kessing LV, Faurholt-Jepsen M. Smartphone-based self-assessment of stress in healthy adult individuals: a systematic review. J Med Internet Res 2017 Feb 13;19(2):e41. [doi: 10.2196/jmir.6397] [Medline: 28193600]

8. Cohen S, Kamarck T, Mermelstein R. A global measure of perceived stress. J Health Soc Behav 1983 Dec;24(4):385-396. [doi: 10.2307/2136404] [Medline: 6668417 ]

9. Lee E. Review of the psychometric evidence of the perceived stress scale. Asian Nurs Res (Korean Soc Nurs Sci) 2012 Dec;6(4):121-127. [doi: 10.1016/j.anr.2012.08.004] [Medline: 25031113]

10. Ingram PB, Clarke E, Lichtenberg JW. Confirmatory factor analysis of the perceived stress scale-4 in a community sample. Stress Health 2016 Apr;32(2):173-176. [doi: 10.1002/smi.2592] [Medline: 24995556]

11. Vallejo MA, Vallejo-Slocker L, Fernández-Abascal EG, Mañanes G. Determining factors for stress perception assessed with the perceived stress scale (PSS-4) in Spanish and other European samples. Front Psychol 2018 Jan;9:37 [FREE Full text] [doi: 10.3389/fpsyg.2018.00037] [Medline: 29434563]

12. Levenstein S, Prantera C, Varvo V, Scribano ML, Berto E, Luzi C, et al. Development of the perceived stress questionnaire: a new tool for psychosomatic research. J Psychosom Res 1993 Jan;37(1):19-32. [doi: 10.1016/0022-3999(93)90120-5] [Medline: $\underline{8421257]}$

13. Pryss R, John D, Reichert M, Hoppenstedt B, Schmid L, Schlee W, et al. Machine Learning Findings on Geospatial Data of Users from the TrackYourStress mHealth Crowdsensing Platform. In: Proceedings of the 20th International Conference on Information Reuse and Integration for Data Science. 2019 Presented at: IRI'19; July 30-August 1, 2019; Los Angeles, CA p. 350-355 URL: http://dbis.eprints.uni-ulm.de/1812/ [doi: 10.1109/IRI.2019.00061]

14. Geldhof GJ, Preacher KJ, Zyphur MJ. Reliability estimation in a multilevel confirmatory factor analysis framework. Psychol Methods 2014 Mar;19(1):72-91. [doi: 10.1037/a0032138] [Medline: 23646988] 
15. McNeish D. Thanks coefficient alpha, we'll take it from here. Psychol Methods 2018 Sep;23(3):412-433. [doi: 10.1037/met0000144] [Medline: 28557467]

16. Satow L. Dr Lars Satow. 2012. Stress- und Coping-Inventar (SCI) URL: https://www.drsatow.de/tests/ stress-und-coping-inventar/ [accessed 2019-08-03]

17. Bradley MM, Lang PJ. Measuring emotion: the self-assessment manikin and the semantic differential. J Behav Ther Exp Psychiatry 1994 Mar;25(1):49-59. [doi: 10.1016/0005-7916(94)90063-9] [Medline: 7962581]

18. Pryss R, Schobel J, Reichert M. Requirements for a Flexible and Generic API Enabling Mobile Crowdsensing mHealth Applications. In: Proceedings of the 4th International Workshop on Requirements Engineering for Self-Adaptive, Collaborative, and Cyber Physical Systems. 2018 Oct 22 Presented at: RESACS'18; August 20, 2018; Banff, AB, Canada p. 24-31. [doi: 10.1109/RESACS.2018.00010]

19. Pryss R, Probst T, Schlee W, Schobel J, Langguth B, Neff P, et al. Prospective crowdsensing versus retrospective ratings of tinnitus variability and tinnitus-stress associations based on the TrackYourTinnitus mobile platform. Int J Data Sci Anal 2018 Mar 12:-. [doi: 10.1007/s41060-018-0111-4]

20. Sevil M, Hajizadeh I, Samadi S, Feng J, Lazaro C, Frantz N, et al. Social and Competition Stress Detection With Wristband Physiological Signals. In: Proceedings of the 14th International Conference on Wearable and Implantable Body Sensor Networks. 2017 Jun 1 Presented at: BSN'17; May 9-12, 2017; Eindhoven, Netherlands p. 39-42. [doi: 10.1109/BSN.2017.7936002]

21. Singer JD, Willett JB. Applied Longitudinal Data Analysis: Modeling Change and Event Occurrence. Oxford: Oxford University Press; 2003.

22. Snijders TA, Bosker RJ. Multilevel Analysis: An Introduction to Basic and Advanced Multilevel Modeling. Thousand Oaks, CA: Sage Publications; 2012.

23. Göllner R, Gollwitzer M, Heider J, Zaby A, Schröder A. [Analysis of longitudinal data with hierarchical linear models]. Zeitschrift für Klinische Psychologie und Psychotherapie 2010 Jul;39(3):179-188. [doi: 10.1026/1616-3443/a000032]

24. Schlee W, Pryss RC, Probst T, Schobel J, Bachmeier A, Reichert M, et al. Measuring the moment-to-moment variability of tinnitus: the TrackYourTinnitus smart phone app. Front Aging Neurosci 2016;8:294 [FREE Full text] [doi: 10.3389/fnagi.2016.00294] [Medline: 28018210]

25. Aaron LA, Turner JA, Mancl L, Brister H, Sawchuk CN. Electronic diary assessment of pain-related variables: is reactivity a problem? J Pain 2005 Mar;6(2):107-115. [doi: 10.1016/j.jpain.2004.11.003] [Medline: 15694877]

26. Husky M, Olié E, Guillaume S, Genty C, Swendsen J, Courtet P. Feasibility and validity of ecological momentary assessment in the investigation of suicide risk. Psychiatry Res 2014 Dec 15;220(1-2):564-570. [doi: 10.1016/j.psychres.2014.08.019] [Medline: 25155939]

27. Lakens D. Equivalence tests: a practical primer for t tests, correlations, and meta-analyses. Soc Psychol Personal Sci 2017 May;8(4):355-362 [FREE Full text] [doi: 10.1177/1948550617697177] [Medline: 28736600]

28. Streiner DL. Unicorns do exist: a tutorial on 'proving' the null hypothesis. Can J Psychiatry 2003 Dec;48(11):756-761. [doi: 10.1177/070674370304801108] [Medline: 14733457]

29. John D, Lang FR. Subjective acceleration of time experience in everyday life across adulthood. Dev Psychol 2015 Dec;51(12):1824-1839. [doi: 10.1037/dev0000059] [Medline: 26414094]

30. Heron KE, Smyth JM. Ecological momentary interventions: incorporating mobile technology into psychosocial and health behaviour treatments. Br J Health Psychol 2010 Feb;15(Pt 1):1-39 [FREE Full text] [doi: 10.1348/135910709X466063] [Medline: 19646331$]$

31. Pryss R, Reichert M, John D, Frank J, Schlee W, Probst T. A Personalized Sensor Support Tool for the Training of Mindful Walking. In: Proceedings of the 15th International Conference on Wearable and Implantable Body Sensor Networks. 2018 Presented at: BSN'18; March 4-7, 2018; Las Vegas, NV, USA p. 114-117. [doi: 10.1109/bsn.2018.8329672]

32. Martín MD, de la Torre I, Garcia-Zapirain B, Lopez-Coronado M, Rodrigues J. Managing and controlling stress using mHealth: systematic search in app stores. JMIR Mhealth Uhealth 2018 May 9;6(5):e111 [FREE Full text] [doi: 10.2196/mhealth.8866] [Medline: 29743152]

33. Winslow BD, Chadderdon GL, Dechmerowski SJ, Jones DL, Kalkstein S, Greene JL, et al. Development and clinical evaluation of an mHealth application for stress management. Front Psychiatry 2016 Jul 26;7:130 [FREE Full text] [doi: 10.3389/fpsyt.2016.00130] [Medline: 27507949]

34. Mani M, Kavanagh DJ, Hides L, Stoyanov SR. Review and evaluation of mindfulness-based iPhone apps. JMIR Mhealth Uhealth 2015 Aug 19;3(3):e82. [doi: 10.2196/mhealth.4328] [Medline: 26290327]

35. van Ballegooijen W, Ruwaard J, Karyotaki E, Ebert DD, Smit JH, Riper H. Reactivity to smartphone-based ecological momentary assessment of depressive symptoms (MoodMonitor): protocol of a randomised controlled trial. BMC Psychiatry 2016 Oct 21;16:359 [FREE Full text] [doi: 10.1186/s12888-016-1065-5] [Medline: 27769201]

36. Haim S, Wang R, Lord SE, Loeb L, Zhou X, Campbell AT. The Mobile Photographic Stress Meter (MPSM): A New Way to Measure Stress Using Images. In: Proceedings of the 2015 ACM International Joint Conference on Pervasive and Ubiquitous Computing and Proceedings of the 2015 ACM International Symposium on Wearable Computers. 2015 Presented at: UbiComp/ISWC'15 Adjunct; September 7-11, 2015; Osaka, Japan p. 733-742. [doi: 10.1145/2800835.2804398] 
37. Sharma N, Gedeon T. Objective measures, sensors and computational techniques for stress recognition and classification: a survey. Comput Methods Programs Biomed 2012 Dec;108(3):1287-1301. [doi: 10.1016/j.cmpb.2012.07.003] [Medline: 22921417]

38. DaSilva AW, Huckins JF, Wang R, Wang W, Wagner DD, Campbell AT. Correlates of stress in the college environment uncovered by the application of penalized generalized estimating equations to mobile sensing data. JMIR Mhealth Uhealth 2019 Mar 19;7(3):e12084 [FREE Full text] [doi: 10.2196/12084] [Medline: 30888327]

39. Ben-Zeev D, Scherer EA, Wang R, Xie H, Campbell AT. Next-generation psychiatric assessment: using smartphone sensors to monitor behavior and mental health. Psychiatr Rehabil J 2015 Sep;38(3):218-226 [FREE Full text] [doi: 10.1037/prj0000130] [Medline: 25844912]

40. Choi S, Kim S, Yang JS, Lee JH, Joo C, Jung HI. Real-time measurement of human salivary cortisol for the assessment of psychological stress using a smartphone. Sens Biosens Res 2014 Dec;2:8-11. [doi: 10.1016/j.sbsr.2014.08.001]

41. Mohino-Herranz I, Gil-Pita R, Ferreira J, Rosa-Zurera M, Seoane F. Assessment of mental, emotional and physical stress through analysis of physiological signals using smartphones. Sensors (Basel) 2015 Oct 8;15(10):25607-25627 [FREE Full text] [doi: 10.3390/s151025607] [Medline: 26457710]

42. Pryss R, Reichert M, Schlee W, Spiliopoulou M, Langguth B, Probst T. Differences Between Android and iOS Users of the TrackYourTinnitus Mobile Crowdsensing mHealth Platform. In: Proceedings of the 31st International Symposium on Computer-Based Medical Systems. 2018 Presented at: CBMS'18; June 18-21, 2018; Karlstad, Sweden p. 411-416. [doi: 10.1109/cbms.2018.00078]

43. Pryss R, Schlee W, Reichert M, Kurthen I, Giroud N, Jagoda L, et al. Ecological Momentary Assessment Based Differences Between Android and iOs Users of the TrackYourHearing mHealth Crowdsensing Platform. In: Proceedings of the 41st Annual International Conference of the IEEE Engineering in Medicine \& Biology Society. 2019 Presented at: EMBC'19; July 23-27, 2019; Berlin, Germany p. 3951-3955. [doi: 10.1109/EMBC.2019.8857854]

44. Ubhi HK, Kotz D, Michie S, Schayck OC, West R. A comparison of the characteristics of iOS and Android users of a smoking cessation app. Transl Behav Med 2017 Jun;7(2):166-171 [FREE Full text] [doi: 10.1007/s13142-016-0455-z] [Medline: 28168609]

\section{Abbreviations \\ API: application program interface \\ EMA: ecological momentary assessment \\ EMI: ecological momentary intervention \\ GPS: Global Positioning System \\ ICC: intraclass correlation \\ PSRS: Perceived Stress Reactivity Scale \\ PSS: Perceived Stress Scale \\ RESTful: Representational State Transfer \\ RQ: research question \\ SAM: Self-Assessment Manikins \\ TYS: TrackYourStress}

Edited by G Eysenbach; submitted 11.03.19; peer-reviewed by U Scholz, J Huckins, F Seoane, J Lüscher; comments to author 27.04.19;
revised version received 22.06.19; accepted 19.08.19; published 30.10.19
Please cite as:
Pryss $R$, John D, Schlee W, Schlotz, W, Schobel J, Kraft R, Spiliopoulou M, Langguth B, Reichert M, O'Rourke T, Peters H, Pieh C,
Lahmann C, Probst T
Exploring the Time Trend of Stress Levels While Using the Crowdsensing Mobile Health Platform, TrackYourStress, and the Influence
of Perceived Stress Reactivity: Ecological Momentary Assessment Pilot Study
JMIR Mhealth Uhealth 2019;7(10):e13978
URL: $\underline{\text { http://mhealth.jmir.org/2019/10/e13978/ }}$
doi: $\underline{10.2196 / 13978}$
PMID: $\underline{31670692}$

CRüdiger Pryss, Dennis John, Winfried Schlee, Wolff Schlotz, Johannes Schobel, Robin Kraft, Myra Spiliopoulou, Berthold Langguth, Manfred Reichert, Teresa O'Rourke, Henning Peters, Christoph Pieh, Claas Lahmann, Thomas Probst. Originally published in JMIR Mhealth and Uhealth (http://mhealth.jmir.org), 30.10.2019. This is an open-access article distributed under the terms of the Creative Commons Attribution License (https://creativecommons.org/licenses/by/4.0/), which permits unrestricted 
use, distribution, and reproduction in any medium, provided the original work, first published in JMIR mhealth and uhealth, is properly cited. The complete bibliographic information, a link to the original publication on http://mhealth.jmir.org/, as well as this copyright and license information must be included. 